\title{
Health authority patterns of hospital discharge rates for poisonings in the RHAs of England and the DHAs of Yorkshire, and their relationship to social deprivation
}

\author{
E. B. Renvoize, formerly Consultant Psychiatrist, Bootham Park Hospital, York; \\ (Correspondence to: Dr E. B. Renvoize, Department of Community Medicine, \\ Leeds General Infirmary, Great George Street, Leeds LS1 3EX); A. D. CLAYDEN, \\ Senior Lecturer in Medical Statistics, University of Leeds; and A. W. BEVERIDGE, \\ Consultant Psychiatrist, West Fife District General Hospital, Dunfermline, Fife
}

Currently, resources for acute mental illness services are allocated on the basis of the age, sex and marital status profiles of the catchment population. However, it has been argued (Hirsch, 1988) that mental illness budgets and bed provision should also be weighted according to the socio-demographic characteristics of the local population.

Correlations have been observed between psychiatric admission rates and Jarman 8 under-privileged area (UPA) scores for two regional health authorities (RHAs) and a district health authority (DHA) (Hirsch, 1988; Hacking, 1988). It has been suggested (Hirsch, 1988) that if these correlations are replicated elsewhere, the use of Jarman 8 UPA scores for weighting purposes might become a powerful tool for estimating the potential demand for psychiatric services in every district.

The Jarman 8 Index (Jarman, 1983; 1984) is a composite measure of social deprivation incorporating individual scores on eight indicators identified as reflecting the extent of demand for primary care services, and is based on 1981 census data. The indicators comprise the following variables as a percentage of the resident population in the DHA, as defined by Rice, Irving \& Davies (1984): ethnic minorities; the highly mobile; one parent families; overcrowded households; pensioners living alone; residents under 5; the unskilled and the unemployed. The index is now accepted by most NHS planners as a fair measure of social deprivation, and UPA scores have been calculated for all DHAs in the country (Hirsch, 1988).

The NHS Management Board have accepted that the demands made by patients on acute general hospital services are influenced by social deprivation, and recommended the introduction of the Jarman 8 Index into the Resource Allocation Working Party (RAWP) formula for the planning and financing of such services; but the Board rejected a similar introduction into the RAWP formula for mental illness services. However, the Government White Paper (Working for Patients) has intimated that RAWP is to be replaced by a different system for allocating resources, although it is unclear if social deprivation will be taken into consideration.

One reason given by the NHS Management Board for the rejection of a social deprivation factor is that the rapidly changing patterns of care occurring at present, such as the closure of large psychiatric hospitals and the development of community services, make the interpretation of current activity data on the use of general psychiatric services difficult. We have therefore attempted to avoid this criticism by examining possible correlations at an RHA and

TABLE I

Mean annual hospital discharge rates per 10,000 population in England, for poisonings and toxic effects (ICD 960-989), 1979-1985, by Regional Health Authority*

\begin{tabular}{lcc}
\hline & $\begin{array}{c}\text { Mean annual } \\
\text { hospital discharge }\end{array}$ & \\
Regional Health & $\begin{array}{c}\text { rate/10,000 } \\
\text { population }\end{array}$ & $\begin{array}{c}\text { RHA UPA } \\
\text { Authority }\end{array}$ \\
\hline Nores** \\
North Western & 28.1 & +8.50 \\
Yorkshire & 25.9 & +5.71 \\
Northern & 24.6 & +5.61 \\
Mersey & 21.0 & +2.36 \\
Trent & 20.9 & -4.67 \\
Wessex & 19.3 & -7.48 \\
South East Thames & 18.8 & +2.61 \\
North East Thames & 18.5 & +4.79 \\
West Midlands & 17.8 & -0.87 \\
North West Thames & 17.3 & -2.58 \\
Oxford & 17.0 & -9.00 \\
South Western & 17.0 & -8.05 \\
South West Thames & 15.8 & -10.98 \\
East Anglia & 15.3 & -6.64 \\
\hline & & \\
\hline England and Wales & 20.3 & \\
\hline
\end{tabular}

*Source: HIPE summary tables for 1979-1985

**Population weighted means of district UPA Scores 
TABLE II

Male and female (aged 15 and over) hospital discharges for poisonings (ICD 960-979) in the Yorkshire Regional Health Authority, 1979-1986, by district of residence

\begin{tabular}{lcccc}
\hline & $\begin{array}{c}\text { Mean annual } \\
\text { population over } \\
\text { 15 years of age } \\
\text { (thousands) }\end{array}$ & $\begin{array}{c}\text { Mean annual } \\
\text { no of discharges } \\
1979-86\end{array}$ & $\begin{array}{c}\text { Mean annual } \\
\text { discharge rate) } \\
10,000\end{array}$ & $\begin{array}{c}\text { Jarman } 8 \\
\text { UPA Score }\end{array}$ \\
\hline BHA & 260.1 & 867.5 & 33.4 & +35.75 \\
Bradford & 293.1 & 924.1 & 31.5 & +6.28 \\
Leeds West & 283.1 & 886.1 & 31.3 & +10.25 \\
Leeds East & 238.1 & 701.0 & 29.4 & +18.68 \\
Hull & 152.1 & 440.6 & 29.0 & +13.86 \\
Calderdale & 125.9 & 358.8 & 28.5 & +0.86 \\
Grimsby & 112.5 & 303.8 & 27.0 & -4.26 \\
Wakefield & 134.0 & 337.5 & 25.2 & -8.06 \\
Pontefract & 126.4 & 289.5 & 22.9 & +17.31 \\
Dewsbury & 106.3 & 228.4 & 21.5 & -12.41 \\
Harrogate & 205.8 & 413.6 & 20.1 & -12.82 \\
York & 115.8 & 229.9 & 19.9 & -3.45 \\
Scarborough & 151.8 & 298.3 & 19.7 & -0.30 \\
Scunthorpe & 138.6 & 270.4 & 19.5 & +3.80 \\
Airedale & 159.6 & 236.6 & 14.8 & -21.26 \\
East Yorkshire & 169.4 & 231.9 & 13.7 & +12.62 \\
Huddersfield & 88.6 & 109.6 & 12.4 & -11.40 \\
Northallerton & & & & \\
\hline
\end{tabular}

TABLE III

Spearman's rank correlation coefficient between DHA hospital discharge rates (male and female combined) for poisonings (ICD 960-979) in the Yorkshire RHA 1979-1986, and Jarman 8 UPA scores

\begin{tabular}{lcc}
\hline & $\begin{array}{c}\text { Hospital discharge } \\
\text { rates for poisonings } \\
\text { Variable }\end{array}$ & \\
\hline Jarman 8 UPA score & +0.55 & $P=0.02$ \\
Ethnic minorities & +0.27 & $P=0.30$ \\
Mobility & +0.22 & $P=0.40$ \\
One parent families & +0.79 & $P=0.0001$ \\
Overcrowding & +0.54 & $P=0.03$ \\
Elderly living alone & +0.14 & $P=0.61$ \\
Residents under 5 & +0.37 & $P=0.15$ \\
Unemployment & +0.51 & $P=0.04$ \\
Unskilled & +0.44 & $P=0.08$ \\
\hline
\end{tabular}

DHA level, between a specific aspect of psychiatric bed use-those occupied by parasuicide patients, where we suppose that the bed provision, being usually part of the general hospital pool, has been subject to less change - and the Jarman 8 Index. In this way, using the extent of parasuicide bed use as a proxy indicator of the need for psychiatric bed provision in general, we aimed to test the hypothesis that the value of the Jarman 8 Index is correlated with the extent of in-patient use of mental illness services, justifying its introduction into any mechanism for planning care of the mentally ill.

\section{The study}

The annual hospital discharge rates for each RHA in England for poisonings and toxic effects (ICD-9, 960-989) were identified from the Hospital InPatient Enquiry (HIPE) Summary Tables (Series MB4) for each of the years 1979-1985, and a mean annual hospital discharge rate for the period 1979 1985 was calculated for each Region. Spearman's method was then used to test for a possible correlation between RHA discharge rates and regional Jarman 8 UPA scores.

The total number of male and female hospital discharges for poisonings (ICD-9, 960-979) in those aged 15 and over in the 17 DHAs in Yorkshire, by district of residence, between 1979-1986, were identified from Hospital Activity Analysis (HAA) data, and a mean annual number of discharges for the period calculated for each District. The individual mid-year population estimates (male and female combined) of the $15+$ age groups for the same time interval were used to calculate a mean 1979-1986 annual population estimate for each DHA. A mean annual hospital discharge rate/ 10,000 population for the 15 and over age group was then determined for each DHA, and Spearman's method was used to test 
for possible correlations between these and Jarman 8 overall and sub-scores.

The mean annual hospital discharge rates in England for poisoning and toxic effects by RHA, between 1979-1985, as well as the RHA Jarman 8 UPA scores, are shown in Table I. RHA hospital discharge rates were found to be significantly correlated with the UPA scores (correlation coefficient = $0.80, P<0.001$ ). It may be seen that, for instance, the three Regions with the highest discharge rates also had the highest UPA scores, and three of the four Regions with the lowest discharge rates had the lowest UPA scores.

Table II shows the mean annual hospital discharge rates per 10,000 population for poisonings within each DHA of the Yorkshire RHA, between 19791986, and the DHA Jarman 8 UPA scores. Hospital discharge rates were significantly correlated with Jarman 8 UPA scores $(P<0.05)$. However, the association is less strong for Districts than for Regions, with the four Districts having the highest discharge rates, including two with the highest UPA scores, and the three Districts with the lowest discharge rates, including the one with the lowest UPA score.

Table III shows that DHA hospital discharge rates were also significantly correlated with three of the variables contributing to the Jarman 8: overcrowding $(P<0.05)$, unemployment $(P<0.05)$ and one parent families $(P=0.0001)$. The best correlation was observed for one parent families, with the five Districts with the highest discharge rates also having the highest scores for one parent families, and two of the three Districts with the lowest discharge rates having the lowest scores for one parent families.

\section{Comment}

We have shown that the use of hospital beds for selfpoisoning is significantly associated with social deprivation, as measured by the Jarman 8 Index, both at a regional and a district health authority level. Previous studies (e.g. Platt, 1986; Hawton, 1987) have indicated that hospitalisation rates for self-poisoning are highest in the lower social classes, in urban areas and areas of residential mobility, overcrowding and high unemployment.

As in our study, Hacking (1988) found that of all the measures examined, the percentage of one parent families showed the highest correlation with mental illness admissions in the North Western RHA, and proved to be a better predictor of admissions than the Jarman 8 Index. Further studies may identify superior predictive measures.

Alternative explanations are possible for the association found in the present study, other than that of a direct aetiological link of increased incidence of parasuicide with social deprivation. For example, factors such as the quality of primary care services, the prescribing habits of general practitioners (Forster \& Frost, 1985), the proximity, access and acceptability of hospital provision for this group of patients, and admission policies in accident and emergency departments may also vary with social deprivation, and hence influence hospitalisation rates.

However, whatever the precise explanation(s), our findings suggest that hospital admission rates of a sub group of psychiatric patients are influenced by social deprivation, and that districts of low socioeconomic status are likely to require above-average psychiatric provision for poisonings. They also provide further, albeit indirect, evidence that on the grounds of equity, any new system for allocating funds to RHAs and DHAs for mental illness services, should contain a weighting factor for social deprivation.

\section{References}

Forster, D. P. \& Frost, C. E. B. (1985) Medicinal selfpoisoning and prescription frequency. Acta Psychiatrica Scandinavica, 71, 567-574.

HaCKING, J. (1988) Weighty problem of RAWP. The Health Service Journal, 27, 1268-1269.

Hawton, K. (1987) Attempted suicide. Medicine International, 43, 1786-1790.

HIRSCH, S. R. (1988) Psychiatric Beds and Resources: Factors Influencing Bed Use and Service Planning. London: Gaskell (Royal College of Psychiatrists).

JARMAN, B. (1983) Identification of underprivileged areas. British Medical Journal, 286, 1705-1709.

-(1984) Underprivileged areas: validation and distribution of scores. British Medical Journal, 289, 1587-1592.

Platt, S. (1986) Parasuicide and unemployment. British Journal of Psychiatry, 149, 401-405.

RICE, P., IRVING, D. \& DAVIEs, G. (1984) Information about District Health Authorities in England from the 1981 Census. London: King's Fund Centre. 